\title{
Study on 100 cases of coronary artery disease underwent percutaneous coronary interventions
}

\author{
Mohammad Shafiqur Rahman Patwary ${ }^{1}$, Md Faruque1, Fazlur Rahman², A.Q.M. Reza1 \\ Mizanur Rahman ${ }^{1}$, Sufia Rahman ${ }^{1}$, Abduz Zaher ${ }^{1}$, Md Harisul Hoque ${ }^{2}$ \\ ${ }^{1}$ Department of Cardiology, National Institute of Cardiovascular Disease (NICVD), Dhaka \\ ${ }^{2}$ Department of Cardiology, UCC, Bangabandhu Sheikh Mujib Medical University, Dhaka \\ Address for Correspondence \\ Dr. Mohammad Shafiqur Rahman Patwary, Department of Cardiology, National \\ Institute of Cardiovascular Disease (NICVD), Dhaka \\ Email: dr_md_shafiqur_rahman@yahoo.com
}

\begin{abstract}
This prospective study was done in National Institute of Cardiovascular Diseases, Dhaka, Bangladesh during the period of January 2004 to January2005 to see the effectiveness and safety profile of percutaneous coronary interventions in patients with coronary artery disease. 100 patients with male 90 percent and female 10 percent undergo percutaneous coronary intervention in our unit during this period. Indication of percutaneous coronary interventions were chronic stable angina with stress test positive in 20 percent cases, unstable angina with prior myocardial infarction in 30 percent cases, unstable angina without prior myocardial infarction in 20percent cases, acute inferior myocardial infarction with post myocardial infarction angina in 20 percent cases and acute anterior myocardial infarction with post myocardial infarction angina in 10 percent cases. Angiographic diagnosis of the patients were single vessel disease in 70 percent cases, double vessel disease in 24 percent cases and triple vessel disease in 11 percent cases. Total number of disease coronary arteries was 146 and 125 lesions were treated. Out of 125, 120 lesions were treated with percuteneous transluminal coronary angioplasty with stenting and 5 lesions with plain percuteneous transluminal coronary angioplasty. Total occlusion was treated in 7 cases. Mean diameter of stent used was $3.02 \pm 0.42 \mathrm{~mm}$. Patients were discharged by three to four days of the procedure with improved clinical conditions.Residual stenosis after deploying of stent was less than 10 percent. Our angiographic success rate was 98 percent, procedural success 96 percent and clinical success 95 percent. Failed percuteneous transluminal coronary angioplasty in 2 cases all of them were chronic total occlusion. One patient died on third day of the procedure due to ventricular asystole, he was a patient of triple vessel disease. Following procedure, course of the patients were uneventful. In the field of maagement of coronary artery disease percutaneous coronary intervention is the internationally recognized standard treatment worldwide for more than last 2 decades. From our result it is found that in most of the indicated cases of PCI can be done efficiently with very minimum rate of failure \& complication.
\end{abstract}

Key word: Percutaneous coronary interventions, coronary artery disease.

\section{Introduction}

Coronary angioplasty was first introduced by Andreas Gruentzig in 1977 as a non-surgical method for coronary arterial revascularization ${ }^{1}$. Fundamentally the technique involved advancing a balloon tipped catheter to an area of coronary narrowing, inflating the balloon \& then removing the catheter following deflation. Early reports demonstrated that balloon angioplasty could reduce the severity of coronary stenosis \& diminish or eliminate objective \& subjective manifestations of ischemia ${ }^{2,3,4}$. Although angioplasty was clearly feasible \& effective, the scope of coronary disease to be treated was quite narrow. Also, angioplasty could result in sudden arterial occlusion \& subsequently myocardial infarction (MI), immediate access to coronary bypass surgery was essential ${ }^{5}$. Day by day with experience $\&$ time, the cognitive $\&$ technical aspects as much as the equipment used to perform angioplasty became more refined.

Now coronary angioplasty could be applied to broad groups of coronary patients with higher rate of success \& lower rates of complications when compared to initial experience 6,7 .

Percutaneous coronary interventions (PCI) are an important group of technologies. Initially Percutaneous coronary interventions limited to balloon angioplasties \& termed percuteneous transluminal coronary angioplasty (PTCA). Percutaneous coronary interventions now includes other new techniques capable of reliving coronary narrowing including implantation of intracoronary stents, rotational atherectomy, directional atherectomy, extraction atherectomy, laser angioplasty \& other catheter devices for treating coronary athersclerosis.

\section{Materials and methods}

This prospective observational study was done in National Institute of Cardiovascular Disease (NICVD), Dhaka, Bangladesh, during the period of January 2004 to January 2005. Aims of this study were to see the effectiveness and safety profile of percutaneous coronary interventions in patients with coronary artery disease. 100 consecutive 
patients of symptomatic coronary artery disease underwent percutaneous coronary interventions in our unit were selected for the present study. Indications of percutaneous coronary interventions were chronic stable angina with stress test positive, unstable angina with prior myocardial infarction, unstable angina without prior myocardial infarction, acute inferior myocardial infarction with post myocardial infarction angina and acute anterior myocardial infarction with post myocardial infarction angina. From this group of patients,angiographically significant coronary artery disease patients with suitable lesion for percutaneous coronary interventions were included in this study.Exclusion criteria of this study were left main disease, lesion are not suitable for percutaneous coronary interventions and associated any co-morbid condition .

Angiographic success was explain as stenosis diameter reduction to $<20 \%$. Procedural success of this study means achievement of angiographic success without in hospital major clinical complications e.g. death, myocardial infarction, emergency coronary artery bypass surgery during hospitalization 2,8 . Clinical success means successful percutaneous coronary interventions includes anatomic \& procedural success with relief of signs and or symptoms of myocardial ischemia after the patient recovers from the procedure. Procedural complications are divided into six basic categories: death, myocardial infraction, emergency coronary artery bypass graft, stroke, vascular access site complications and contrast agent nephropathy ${ }^{9}$.

\section{Procedure}

All the procedures were done through right femoral arterial approach using 7F guiding catheters most frequently Judkins in some cases with extra back up catheters, with premedication of aspirin, clopidogrel, anti-ischemic therapy and statin. Beginning of procedure a bolus of 10,000 unit heparin given \& activated clotting time (ACT) was done after 10 minutes \& it was maintained around 300 during the whole procedure by giving 5000 unit heparin hourly. $90 \%$ of the lesion was predilated by balloons before deploying stents. Balloon expandable stents were used in all the cases. Femoral sheaths were removed within 4-6 hours of the procedure. In all cases post procedure heparin used. Clopidogrel was used in all patients. During hospital discharge all patients were prescribed with aspirin $150 \mathrm{mg}$ daily, clopidogrel $150 \mathrm{mg}$ daily, anti ischemic therapy and statin .

\section{Results}

100 consecutive patients of symptomatic coronary artery disease underwent percutaneous coronary interventions in our unit were selected for the present study. The age range of the patients was from 28-70 years with a mean of 50.59 \pm 7.69 yrs. 90 patients were male and 10 patients were female with a male female ratio of 9:1. Left ventricular ejection fraction was as low as $35 \%$ with a mean of $47 \pm$ $10.5 \%$.Mean Coronary artery diameter was $3.03 \pm 0.53 \mathrm{~mm}$ $\&$ no stent was deployed in vessels caliber less than $2.5 \mathrm{~mm}$, lesion $>38 \mathrm{~mm}$, in cases of extreme tortusity, thrombus at the site of the lesion.

The risk factors of the study population were smoking in $65 \%$ cases, hypertension in $52 \%$ cases, diabetes mellitus in $34 \%$ cases, hyperlipidemia in $30 \%$ cases, and positive family history of ischemic heart disease in $25 \%$ cases (Table-1).

Table 1: Risk factors profile of the study population

\begin{tabular}{|l|l|l|}
\hline Parameter & Na of Patients(N-100) & Percent \\
\hline Smoking & 65 & 65 \\
\hline Hypertension & 52 & 52 \\
\hline Diabetes Mellitus & 34 & 34 \\
\hline Hyperlipidemia & 30 & 30 \\
\hline Positive family history & 25 & 25 \\
\hline
\end{tabular}

Clinical diagnosis of study populations were chronic stable angina with stress test positive in 20 percent cases, unstable angina with prior myocardial infarction in 30 percent cases, unstable angina without prior myocardial infarction in 20 percent cases, acute inferior myocardial infarction with post myocardial infarction angina in 20 percent cases and acute anterior myocardial infarction with post myocardial infarction angina in 10 percent cases (Table-2).

Table 2: Clinical diagnosis of the study population

\begin{tabular}{|c|c|c|}
\hline Parameter & $\begin{array}{c}\text { No. of Patients } \\
\text { (N-100) }\end{array}$ & Pereent \\
\hline $\begin{array}{l}\text { Clronic stable argina with stress test } \\
\text { positive }\end{array}$ & 20 & 20 \\
\hline $\begin{array}{l}\text { Urobable angina with price myocardial } \\
\text { infarction }\end{array}$ & 30 & 30 \\
\hline $\begin{array}{l}\text { Unstable angina without frioe } \\
\text { myocardial infaretion }\end{array}$ & 20 & 20 \\
\hline $\begin{array}{l}\text { Acute infarior myocardial infarctice } \\
\text { with poes moveardial incarcticen angina }\end{array}$ & 20 & 20 \\
\hline $\begin{array}{l}\text { Acule anturior myocardial infarction } \\
\text { with poed myocardial infarction an fins }\end{array}$ & 10 & 10 \\
\hline
\end{tabular}

Angiographic diagnosis of the study population showed single vessel disease in 65 percent cases, double vessel disease in 24 percent cases and triple vessel disease in 11 percent cases (Table-3).

Table 3: Angiographic diagnosis of the study population

\begin{tabular}{|l|l|l|}
\hline Parameter & No. of Patieats (N-100) & Perecat \\
\hline Single vessel discase & 65 & 65 \\
\hline Double vursel discase & 24 & 24 \\
\hline Triple vessel discase & 11 & 11 \\
\hline
\end{tabular}

Table-4 showed total number of diseased coronary artery were 146 . Out of this, 120 coronary artery were treated 
.Total number of lesion were152.Out of this 125 lesions were treated. 120 lesions were treated with percuteneous transluminal coronary angioplasty with stenting . Rest of the lesions were treated with plain percuteneous transluminal coronary angioplasty. 7 cases had total occlusion of the coronary artery. Mean diameter of vessel was $3.02 \pm 0.42$ $\mathrm{mm}$.

\section{Table 4: Distribution of coronary artery lesions of the study population}

\begin{tabular}{|l|l|}
\hline Parameters & Numerieal Value \\
\hline Total number of diseased coronary artery & 146 \\
\hline Total number of lesion & 152 \\
\hline Treated sorcnary artery & 120 \\
\hline Treated lesion & 125 \\
\hline Troated with PTCA with stenting & 120 \\
\hline Treated with plain PTCA & 05 \\
\hline Total coslusion was treated & 07 \\
\hline Mean diameter of vessel & $3.02 \pm 0.42 \mathrm{~mm}$ \\
\hline
\end{tabular}

Table -5 showed, 122 stents were used in the study population. Mean diameter of the stent was $2.70 \pm 0.53 \mathrm{~mm}$, majority of the stents were $3.0 \mathrm{~mm}$ diameter. Length of the stents was within the range of $10-18 \mathrm{~mm}$.Majority stents were bare metal stent $(70 \%)$.

\section{Table 5: Characteristics of stent used in the study} population

\begin{tabular}{|l|l|l|}
\hline \multicolumn{2}{|l|}{ Parameters } & Numerical Value \\
\hline Total no of stent & 122 \\
\hline Diameter of the slent & $2.5 \mathrm{~mm}$ & 45 \\
\cline { 2 - 3 } & $2.75 \mathrm{~mm}$ & 12 \\
\cline { 2 - 3 } & $3.0 \mathrm{~mm}$ & 50 \\
\cline { 2 - 3 } & $3.5 \mathrm{~mm}$ & 15 \\
\hline Length of the stents used & $10-38 \mathrm{~mm}$ \\
\hline
\end{tabular}

Table - 6 showed, 53 stents were inflated in right coronary artery, 50 stents in left anterior descending artery and 19 stents in left circumflex artery.

Table 6: Distribution of coronary stent (n-122)

\begin{tabular}{|c|c|c|}
\hline \multicolumn{2}{|l|}{ Coronary artery } & \multirow{2}{*}{\begin{tabular}{|l} 
Na. of sten \\
25 \\
\end{tabular}} \\
\hline \multirow{4}{*}{$\begin{array}{l}\text { Right eoconary artery (RCA) } \\
53 \text { stents }\end{array}$} & Proximal RCA & \\
\hline & Mid RCA & 14 \\
\hline & Distal RCA & 12 \\
\hline & PDA & 02 \\
\hline \multirow{3}{*}{$\begin{array}{l}\text { Left anterior descending } \\
\text { (LAD) } 50 \text { stents }\end{array}$} & Proximsi L.AD & 24 \\
\hline & Mid L.AD & 25 \\
\hline & Distal LAD & 01 \\
\hline \multirow{5}{*}{$\begin{array}{l}\text { Left circumflex (LCX) } \\
\text { 19 stents }\end{array}$} & \begin{tabular}{|l} 
Proximal LCX \\
\end{tabular} & 01 \\
\hline & \begin{tabular}{|l} 
Mid LCX \\
\end{tabular} & DS \\
\hline & Distal LAD & 03 \\
\hline & Obtuso marginal (OM)l & 04 \\
\hline & Qtowse marginal (OM)2 & 03 \\
\hline
\end{tabular}

Residual stenosis after deploying stent was less than 10 percent. Failed percutaneous coronary interventions in 2 cases all of them were chronic total occlusion not crossed by percuteneous transluminal coronary angioplasty wire. 2 patients developed dissection, of which required immediate intracoronary stents deployment. One patient developed acute LVF on the table \& was managed with IV nitrate, IV frusemide immediately. One patient developed acute inferior myocardial infarction and treated with streptokinase (Table- 7). One patient died on 3rd day of the procedure; he was a patient of triple vessel disease. Following procedure, course of the patients were uneventful. Patients were discharged by three to four days of the procedure with improved clinical conditions

Table 7: In hospital complications of the study population

\begin{tabular}{|c|c|c|}
\hline Parameter & $\begin{array}{c}\text { Ne. of Patients } \\
\text { (N-100) }\end{array}$ & Percent \\
\hline Acute dissection requiring 2 nd stents & 02 & 02 \\
\hline Aoube Left ventricular failure & 01 & 01 \\
\hline Aoute Myocurdial infurction & 01 & 01 \\
\hline 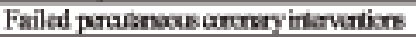 & 02 & 02 \\
\hline Mortality & 01 & 01 \\
\hline
\end{tabular}

Angiographic success rate was $98 \%$, procedural success was $96 \%$ \& clinical success was $95 \%$ (Table- 8 ).

Table8: Results of PCI of the study population Discussion

\begin{tabular}{|l|l|l|}
\hline Parameter & Ne. of Patients(N-100) & Pereent \\
\hline Angiographic sucoess & 98 & 98 \\
\hline Procedural suocess & 96 & 96 \\
\hline Clinical success & 95 & 95 \\
\hline
\end{tabular}

\section{Disucussion}

From this result it is found that most of the patients are male $(90 \%)$, common risk factors are smoking $(65 \%)$ and hypertension (52\%). $80 \%$ had myocardial infraction either acute or old. Angiographic diagnosis of the study population showed single vessel disease was common (65\%). Total numbers of diseased coronary artery were 146.120 lesions were treated with percuteneous transluminal coronary angioplasty with stenting .Rest of the lesions were treated with plain percuteneous transluminal coronary angioplasty. 7 cases had total occlusion of the coronary artery. 122 stents were used in the study population, majority of the stents were $3.0 \mathrm{~mm}$ diameter. Length of the stents was within the range of $10-18 \mathrm{~mm}$. Most of the stents were bare metal stent $(70 \%) .53$ stents were inflated in right coronary artery and 50 stents in left anterior descending artery. Residual stenosis after deploying stent was less than 10 percent. In hospital complications developed in 5\% cases and mortality was $1 \%$. Failed percutaneous coronary interventions in $2 \%$ cases all of them were chronic total occlusion not crossed by 
percuteneous transluminal coronary angioplasty wire. 2 patients developed dissection, of which required immediate intracoronary stents deployment. One patient developed acute left ventricular failure on the table \& was well managed. One patient developed acute inferior myocardial infarction and treated with streptokinase .One patient died on 3rd day of the procedure; he was a patient of triple vessel disease. Following procedure, course of the patients were uneventful. Patients were discharged by three to four days of the procedure with improved clinical conditions. Angiographic success rate was $98 \%$, procedural success was $96 \%$ \& clinical success was $95 \%$.In most of the indicated cases of percutaneous coronary interventions can be done efficiently with very minimum rate of failure \& complication.

Improvements in balloon technology with the increased use of stents and glycoprotein IIb/IIIa platelet receptor antagonists 10,11 have favorably influenced acute procedural out come. This combined balloon with device \& pharmacological approach to coronary intervention in selective procedures has resulted in angiographic success rates of $96-99 \%$ with Q-wave myocardial infraction rates of 1-3\%, emergency coronary artery bypass graft rate 0.2 to $3 \%$ unadjusted inhospital mortality rates 0.5 to $1.4 \%$.. One study 12 here showed angiographic success rate was $96 \%$ with procedural success $94 \%$ and clinical success $90 \%$. Failed percuteneous transluminal coronary angioplasty was in $4 \%$ cases, all of which were chronic total occlusions. $1 \%$ patient developed acute left ventricular failure and $1 \%$ in hospital mortality. Both studies were compatible with our study.

\section{Conclusion}

Percutaneous coronary intervention is the recognized therapies in the management of coronary artery disease with mortality and morbidity benefit. Our result of percutaneous coronary intervention correlates well with the other studies here and abroad, though the study population is small. However the additional iatrogenic disease instent stenosis is one of the drawbacks of the percutaneous coronary intervention, it may be overcome to some extent with drug eluting stent. From this study it is found that in most of the indicated cases of percutaneous coronary intervention can be done efficiently with very minimum rate of failure \& complication. So, percutaneous coronary interventions are the safe and effective procedure in the management of patients with coronary artery disease.

\section{References}

1. Gruesntzig AR, Senning A, Siegenthaler WE. Nonoperative dilation of coronary artery stenosis: percutaneous transluminal coronary angioplasty. $N$ Engl J Med 1979; 301: 61-8.

2. Kent KM, Bentivoglio LG, Block PC, et al. Percutaneous transluminal coronary angioplasty report from the Registry of the National Heart, Lung and Blood Institute. Am J Cardiol 1982; $49: 2011-20$.

3. Williams DO, Riley RS, Singh AK, Most AS. Restoration of normal coronary hemodynamics and myocardial metabolism after percutaneous translumial coronary angioplasty. Circulation 1980; 62 :653-6.

4. Miller DD, Veram MS. Current status of myocardial perfusion imaging after percutaneous transluminal coronary angioplasty. J Am Coll Cardiol 1994; 24:260-6.

5. Detre KM, Holmes DR, Jr, Holubkov R, et al. Incidence and consequences of periprocedural occlusion: the 1985-1986 National Heart, Lung and Blood Institute. Percutaneous Transluminal Coronary Angioplasty Registry. Circulation 1990; $82: 739-50$.

6. Detre KM, Holubkov R, Kelsey S, et al. Percutaneous transluminal coronary angioplasty in 1985-1986 and 1977-1981: The National Heart, Lung and Blood Institute Registry. $N$ Engl J Med 1983; 318: 265-70.

7. O'Keefe JH, Jr. Rutherford BD, McConahay DR, et al. Multivessel coronary angioplasty from 1980 to 1989: procedural results and long-term outcome. J Am Coll Cardiol 1990;16:1097-102.

8. Guidelines for percurtaneous transluminal coronary angioplasty: a report of the American College of Cardiology/American Heart Association Task Force on Assessment of Diagnostic and Tehrapeutic Cardiovascular Procedures (Committee no Percutaneous Transluminal Coronary Angioplasty). J Am Coll Cardiol 1993; 22: 2033-54.

9. Platelet glycoprotein Ilb/IIIa receptor blockade and low-dose heparin during percutaneous coronary revascularization: the EPILOG Investigators. $N$ Engl Med 1997; 336 : 1689-96.

10. Serruys PW, de Jaegere P, Kiemeneij F, et al. A comparison of balloon-expandable-stent implantation with balloon angioplasty in patients with coronary artery disease: Benestent Study Group. N Engl J Med 1994; 331:489-95.

11. Bairn DS, Cutlip DE, Sharma SK, et al. Final results of the Balloon vs. Optimal Atherectomy Trial (BOAT). Circulation 1998; 97:322-31.

12. Uddin M R ,Chowdhury A H K, Ali M et al. Percutaneous Coronary Intervention- (PCI) Result of 100 Cases. Bangladesh Heart Journal 2003; 18(2): 109-115. 